\title{
Poroelastic modeling to assess the effect of water injection for land subsidence mitigation
}

\author{
M. Aichi and T. Tokunaga \\ Graduate School of Frontier Sciences, University of Tokyo, 5-1-5 Kashiwanoha, Kashiwa-shi, Chiba, \\ 277-8563, Japan \\ Correspondence to: M. Aichi (aichi@k.u-tokyo.ac.jp)
}

Published: 12 November 2015

\begin{abstract}
The possible effect of water injection to mitigate land subsidence was studied through numerical simulations based on the theory of poroelasticity. The Kujukuri Plain, Japan, was chosen as a study area. The effect of past injection was evaluated by comparing a model with injection and the one without injection. The calculated results suggested that the past injection played a significant role to reduce land subsidence. For achieving more effective mitigation practices in the future, we proposed to install injection wells in shallower formations. The effect of proposed injection method to mitigate land subsidence from 2014 to 2030 was also investigated. The calculated results show that the proposed method can work similarly by lesser water injection than the past method. The results also indicate that the upper limit of injection rate should be carefully determined to control the pore pressure build-up in the formation to be small enough to avoid formation failure.
\end{abstract}

\section{Introduction}

The production of natural gas and iodine dissolved in groundwater has continued for more than 50 years at the $\mathrm{Ku}$ jukuri Plain, Japan, and it has caused land subsidence problem in the area. To mitigate land subsidence, water injection has been conducted. Several studies (e.g., Horiguchi, 1998) reported that the rate of land subsidence became slower after the start of water injection. However, the impact of water injection has not yet been evaluated properly because other countermeasures such as the reduction of groundwater abstraction were also implemented at the same time, and it was difficult to discriminate the effect of each method from the measured rate of land subsidence. In addition, the design of spatial distribution of injection wells was not optimised because the injection wells were mainly converted from abandoned production wells. This approach also has caused a risk of reservoir deterioration because the formations into which water has been injected are the same as those from which natural gas and iodine are produced.

Thus, it is important to examine the design of water injection wells, both in spatial and injection scheme points of views, to make the mitigation of land subsidence more effective. In this study, water injection into shallower formations

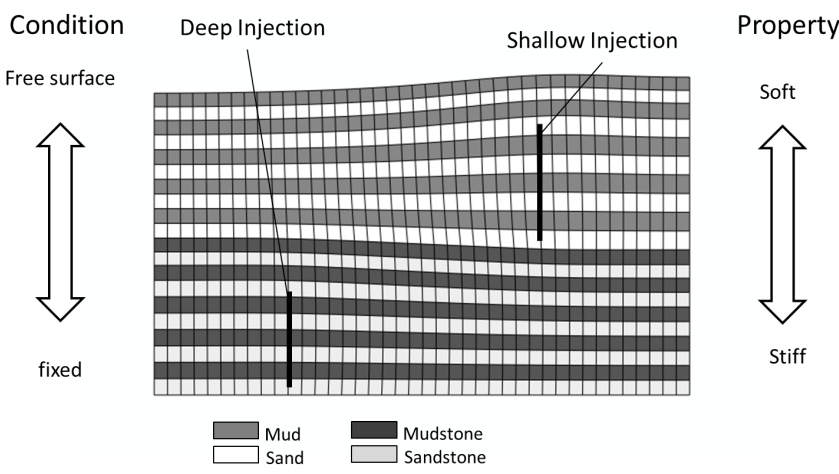

Figure 1. Schematic figure showing the deformation behaviour of the formation by injection. Note that water injection in shallower formations contributes more to the surface displacement compared to that in deeper formations.

is proposed and its effect is quantitatively examined. There exist two expected advantages in the proposed method compared to the current method. One is that the shallower formations are more compliant than reservoirs and another is that the contribution of the deformation of shallower formation is larger to the displacement of land surface (Fig. 1). 
Table 1. The formations and screen intervals in the model.

\begin{tabular}{lrrll}
\hline Formation & Depth (m) & $\begin{array}{r}\text { Sand } \\
\text { ratio }\end{array}$ & $\begin{array}{l}\text { Production } \\
\text { wells }\end{array}$ & $\begin{array}{l}\text { Shallow } \\
\text { injection }\end{array}$ \\
\hline $\begin{array}{l}\text { Soil } \\
\text { Kokumoto } \\
\text { Upper Umegase }\end{array}$ & $\begin{array}{r}-1 \\
-150 \text { to }-80\end{array}$ & & 0.30 & \\
\hline Middle Umegase & -200 to -150 & 0.30 & & screen \\
\hline $\begin{array}{l}\text { Lower Umegase } \\
\text { Upper Ohtadai }\end{array}$ & -455 to -400 & $0.08-0.44$ & screen & \\
\hline $\begin{array}{l}\text { Lower Ohtadai } \\
\text { Kiwada }\end{array}$ & & & & \\
$\begin{array}{l}\text { Ohara } \\
\text { Namihana }\end{array}$ & -1250 & $0.17-0.36$ & & \\
\hline Miura Group & -1500 & & & \\
\hline
\end{tabular}

To quantitatively discuss the effect of water injection into the shallower formations on land subsidence mitigation, a numerical modelling which can calculate the coupled process of both groundwater flow and deformation in subsurface formations is one of the approaches which we can use. There have been several numerical models applied to this area to study the processes around production wells (e.g., Tazaki, 1988, 1994) and regional land subsidence (Nakagawa et al., 2010). However, the effects of injection wells have not been carefully studied. In this study, the effect of past and possible furture water injection is investigated through poroelastic simulations at K-district (Fig. 2, Table 1).

\section{Methodology}

\subsection{Poroelastic modelling}

The set of governing equations used in this study is written as:

$$
\begin{aligned}
& \frac{\partial}{\partial x_{j}}\left[G\left(\frac{\partial u_{j}}{\partial x_{i}}+\frac{\partial u_{i}}{\partial x_{j}}\right)+\frac{2 G v}{1-2 v} \frac{\partial u_{k}}{\partial x_{k}} \delta_{i j}-\alpha p \delta_{i j}\right] \\
& +\rho g_{i}=0, \\
& \frac{\partial}{\partial t}\left[\alpha \frac{\partial u_{k}}{\partial x_{k}}+S_{\varepsilon} p\right]=\nabla\left(\frac{k}{\mu} \nabla p\right)+Q,
\end{aligned}
$$

which is based on the theory of poroelasticity (Biot, 1941), where $G$ is shear modulus, $v$ is drained Poisson's ratio, $\alpha$ is Biot-Willis coefficient, $\rho$ is bulk density of porous media, $S_{\varepsilon}$ is specific storage under constant volumetric strain condition, $k$ is intrinsic permeability, $\mu$ is viscosity of fluid, $u_{i}$ is displacement vector, $g_{i}$ is gravity acceleration vector, $p$ is excess pore pressure and $Q$ is source term where the injection is taken to be positive. To solve the Eqs. (1) and (2) simultaneously, ABAQUS (Dassault Systèmes) was used in this study.

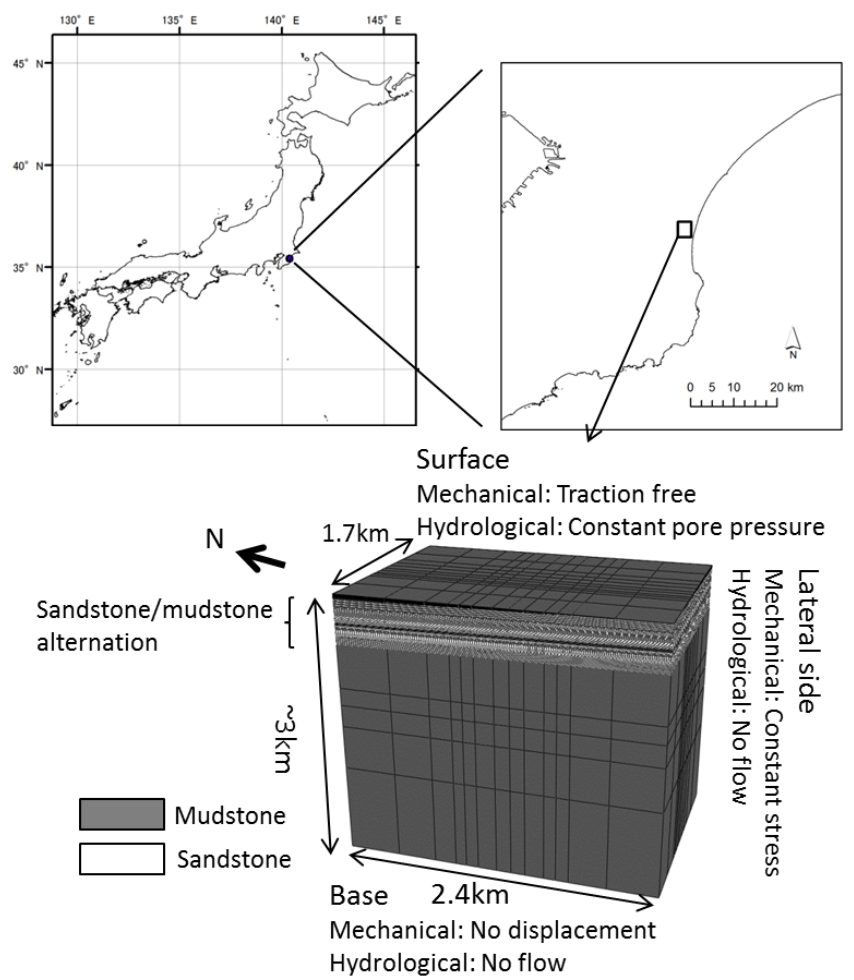

Figure 2. Location of K-district and overview of the model with boundary conditions used in this study.

\subsection{Geological model and physical properties}

The distribution of subsurface formations and physical parameters in the model were based on the JARAS/3D model (Nakagawa, 2010). The overview of the developed model is shown in Fig. 2. The drained Young's moduli were set to be dependent on depth, and were calculated from the following relation:

$E=(350-z) / 0.64[\mathrm{MPa}]$,

where $z$ is the elevation. The drained Poisson's ratio was assumed to be $v=0.3$. The Biot-Willis coefficient and specific storage under constant volumetric strain condition were calculated by assuming that the unjacketed bulk modulus is $36 \mathrm{GPa}$ which is a typical value in Wang (2000). Porosity was assumed to be 0.43 for mudstone and 0.37 for sandstone, respectively, after Tazaki (1988). Permeability of sandstone was set to be $1.5 \times 10^{-14} \mathrm{~m}^{2}$ and that of mudstone was $7.0 \times 10^{-18} \mathrm{~m}^{2}$.

\subsection{Initial and boundary conditions}

The extensive groundwater abstraction for methane and iodine production started in 1963 (Horiguchi, 1998). Because the known excess pore pressure at the initial condition, as reported by Tazaki (1994), was negligibly small compared to the pore pressure changes caused by production, the ini- 


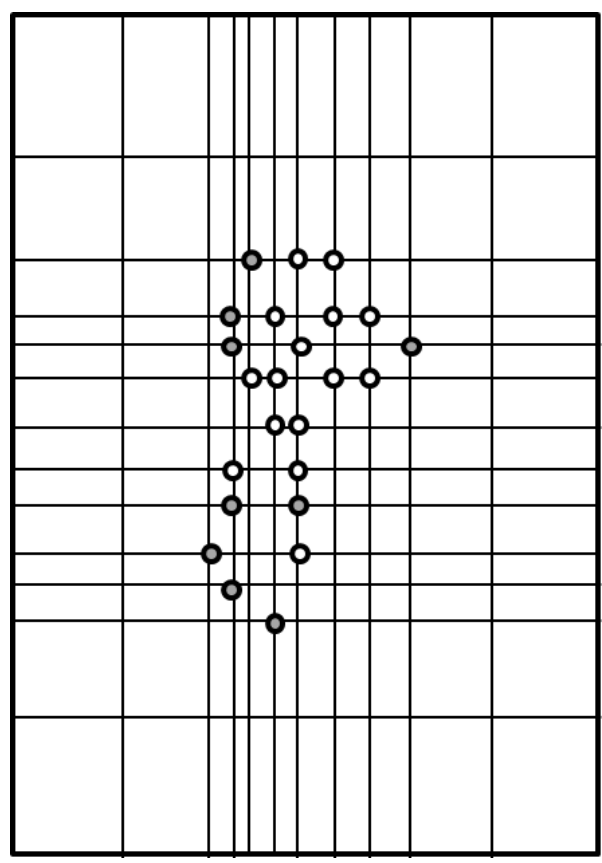

Figure 3. Horizontal view of mesh and the location of wells on the model surface. Open circles indicate the location of production wells or injection wells installed in reservoir. Grey-colored circles indicate the location of both production wells and injection wells installed in shallow formations.

tial condition for the model was set to be hydrostatic in this study.

Boundary conditions are summarized in Fig. 2. The bottom of the model was assumed to be hydrogeological basement and was set to be no flow and no displacement boundary. At the lateral sides, the boundary condition was set to be no flow (Tazaki, 1994) and constant stress. Boundary condition at land surface was set to be constant pore pressure and traction free.

\subsection{Water abstraction and injection}

The spatial distribution of the wells was set after Tazaki (1988) (Fig. 3). The rates of water abstraction and injection at each well were the same order of magnitude and ranged from several thousand to ten thousand cubic meters per month depending on seasons and years. Before 2010, the rates were specified based on the actual production and injection record. After 2010, the rates were assumed to be as same as that in 2009. The screens of production and injection wells converted from the production ones were installed in the lower Umegase and upper Ohtadai Formations (Table 1). The screens of shallow injection wells were installed in the upper Umegase Formation in the model (Table 1).

Three cases were calculated in this study. In the first case, only water production was set in the model and the simulation covered the period from 1963 to 2013. In the second a) With Injection

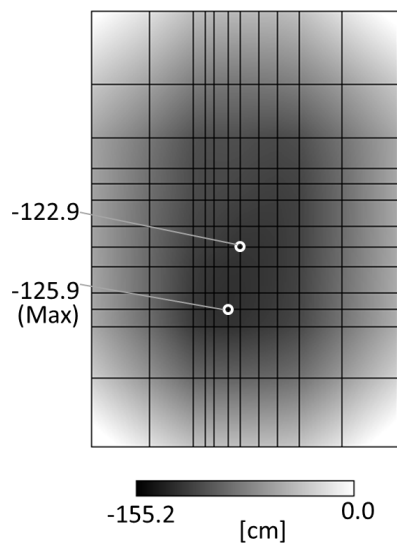

b) Without Injection

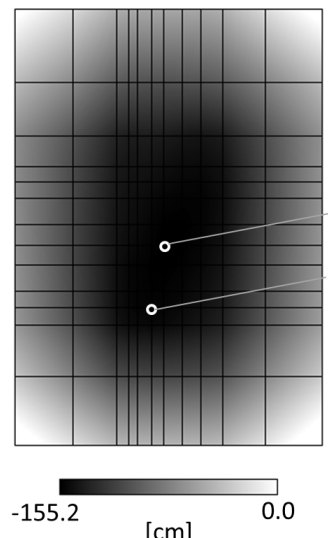

Figure 4. Calculated cumulative land subsidence from 1963 to 2013. (a) Model with injection in reservoir. (b) Model without any injection.

case, both the water production and injection were set in the model and the simulation covered the period from 1963 to 2030. In the third case, the injection in shallow formations was added to case 2 from 2014 to 2030. The effect of past injection was evaluated by comparing cases 1 and 2 . The effect of injection in shallow formations to mitigate land subsidence from 2014 to 2030 was discussed by comparing cases 2 and 3 .

\section{Results and discussions}

\subsection{The effect of past injection}

The results of cases 1 and 2 are compared in Fig. 3. The contribution of past water injection to the reduction of land subsidence was found to be about $30 \mathrm{~cm}(20 \%)$ at the point of maximum subsidence. This suggests that the past injection played a significant role to reduce land subsidence.

\subsection{The effect of injection in shallower formations}

The results of cases 2 and 3 are compared in Fig. 4. The calculated results showed that injecting $5 \%$ of abstracted groundwater reduced about $2 \mathrm{~cm}$ at the site of maximum cumulative subsidence from 2014 to 2030. An injection of $10 \%$ of the abstracted groundwater into shallow formations reduced $4 \mathrm{~cm}(25 \%)$ of the maximum possible land subsidence (Fig. 5). The results indicate that the proposed method provides an effect similar to deep injection into reservoir formations with less water injection.

The pore pressure build-up due to injection is shown in Fig. 6. Until injecting $10 \%$ of abstracted groundwater, the excess pore pressure does not appear. However, if $50 \%$ of abstracted groundwater is injected into shallow formations, the excess pore pressure becomes almost as large as the overburden stress while the land uplift is about $13.5 \mathrm{~cm}$ at the maxi- 

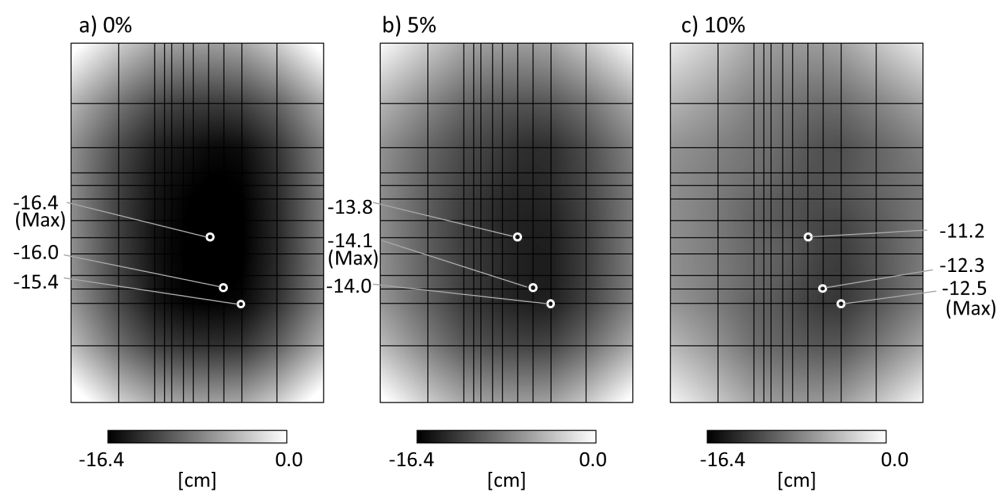

Figure 5. Calculated cumulative land subsidence from 2014 to 2030 in case 3. (a) No injection (case 2 for reference). (b) Injection of $5 \%$ of abstracted water. (c) Injection of $10 \%$ of abstracted water.
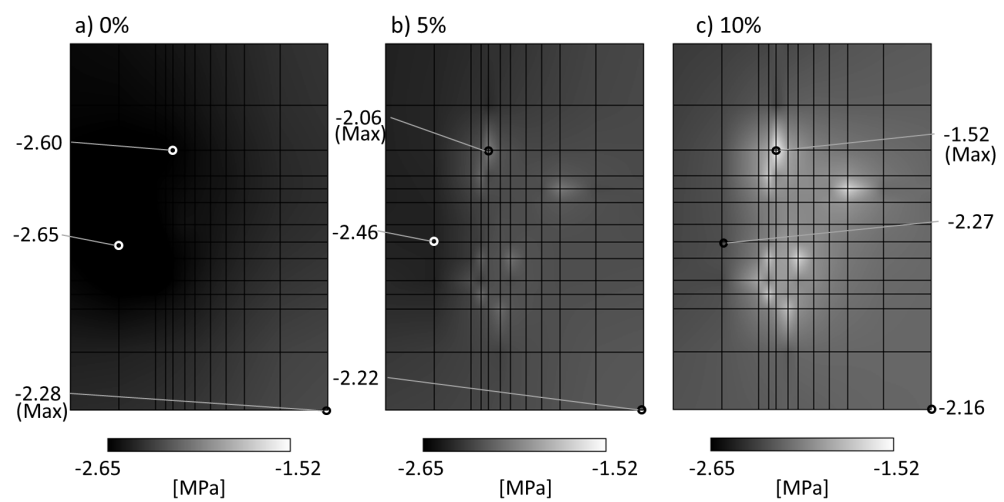

Figure 6. Calculated excess pore pressure at the Middle Umegase Formation in 2030 caused by water injection into shallow formations. (a) No injection in shallow formations (case 2 for reference). (b) Injection of $5 \%$ of abstracted water. (c) Injection of $10 \%$ of abstracted water.

a) Pore pressure

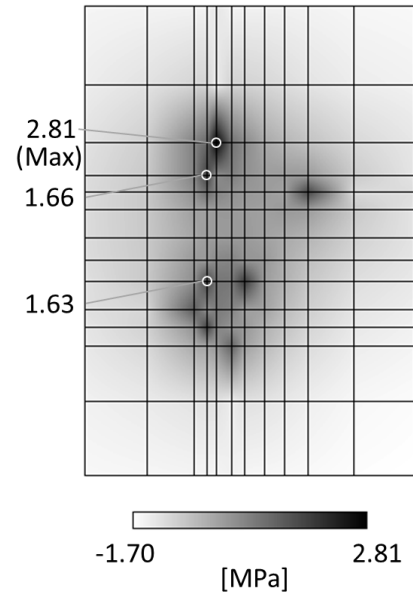

b) displacement

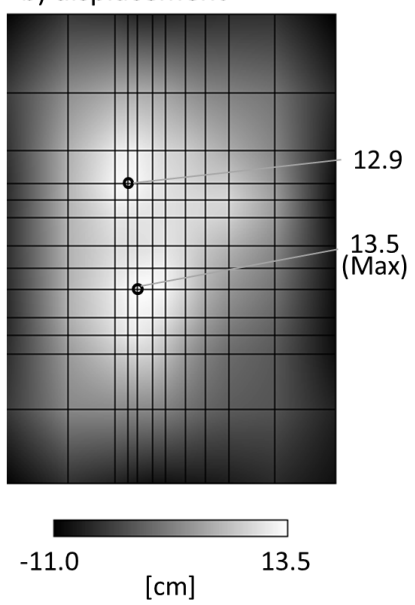

Figure 7. Calculated cumulative land subsidence from 2014 to 2030 and excess pore pressure at the Middle Umegase Formation in 2030 with the water injection of $50 \%$ of abstracted water in shallow formations.

mum (Fig. 7) which is far less than the past cumulative land subsidence (Fig. 3). It indicates that the upper limit of injection rate should be carefully determined to keep the build-up of the pore pressure small enough to avoid formation failure, and it is difficult to totally cancel out the accumulated land subsidence only by the proposed method.

\section{Conclusions}

To quantitatively evaluate the effect of water injection on mitigating land subsidence, numerical simulations were conducted at the Kujukuri Plain, Japan. The past water injection was found to reduce about $25 \%$ of the land subsidence. For the possible effective mitigation in the future, water injection into shallow formations are proposed. The proposed injection method reduced $25 \%$ of total land subsidence from 2014 to 2030 by injecting only $10 \%$ of abstracted groundwater. However, the calculated results also suggested that the upper limit of injection rate should be carefully determined to keep the build-up of pore pressure small enough not to induce the formation failure. 
Acknowledgements. This research was done as a part of $\mathrm{Ku}$ jukuri Project II and the authors are grateful to the Kanto Natural Gas Development Co. Ltd. and other members of the Project who support this study.

\section{References}

Biot, M. A.: General theory of three-dimensional consolidation, J. Appl. Phys., 12, 155-164, 1941.

Horiguchi, K.: Outline of water-dissolved natural gas field in Chiba Prefecture, J. Japanese Assoc. Petrol. Technol., 63, 475-484, 1998 (in Japanese).

Nakagawa, T., Suzuki, I., Nojo, M., Ogatsu, T., and Higuchi, T.: Introduction of the JARAS/3D simulator for natural gas dissolved in water, Proceedings of international symposium on land subsidence No.8, Santiago de Queretaro, Mexico, IAHS Publications, $339,140-143,2010$
Tazaki, Y.: Natural gas deposits of dissolved-in-water type and sand/silt system, J. Japanese Assoc. Petrol. Technol., 53, 256264, 1988 (in Japanese).

Tazaki, Y.: Reservoir engineering for water-dissolved natural gas reservoir in the Kanto sedimentary basin, Japan, Doctoral dissertation, Waseda University, 1994 (in Japanese).

Wang, H. F.: Theory of poroelasticity. Princeton University Press, Princeton, 2000. 